\section{Motivational app hits 400,000 downloads}

The free Brush DJ app, which uses music to engage and motivate users to have an effective oral hygiene routine, has kicked off 2020 by receiving its 400,000 th download. The app has also reached people in 204 countries and remains the only dental app in the NHS App Library.

Unfortunately, basic oral hygiene messages are not reaching, or being acted on by everyone in the population. The Brush DJ app is a low-cost part of the solution and can be used with any toothbrush. This makes it sustainable and helps to reduce inequalities.

Founder and CEO of Brush DJ Ltd Ben Underwood, who is also a dentist, said that hitting 400,000 downloads was a fantastic milestone that would not have been possible without all the people who have helped build, test and champion the app.

Following SBRI Healthcare funding in 2019 the Brush DJ team have investigated the feasibility, opportunity for commercialisation and end user acceptance of enhancing the established Brush DJ app, by evaluating several potential new features. Patient, carer and stakeholder feedback was gained to determine the three most desired, technically feasible and commercially viable features. The team are now raising funding to build the enhanced version and help more people around

http://www.brushdj.com/ the world to have a healthy smile.

\section{Dynamic navigation training in Oxford}

Implant dentists who want to take precision and safety to a new level can learn how on new courses in Oxford this year. Presented by Master Clinical Trainer, Dr Amit Mohindra, the first 'Dynamic navigation for precise implant placement' course at White Bridge Dental Practice will be held on 1 May 2020. The practice is conveniently located for clinicians based in the Midlands and south of England. An early bird discount is available for course bookings made by 20 March 2020 .

Delegates are given an overview of the complete process from patient diagnosis to navigated implant treatment, including live surgery observation. Participants have the opportunity to prepare dental implant sites on models and phantom heads and Navident 2.0 with Trace and Place. with dynamic navigation technology,
Navident is manufactured by ClaroNav and distributed in the UK and Ireland by The Dental Imaging Company Limited.

The course in Oxford is part of the Dynamic Navigation Society's expanding UK training programme for 2020. Details of all the latest courses can be obtained by calling The Dental Imaging Company on 0845602 4944, emailing info@ dynamicnavigationsociety.org.uk or at http://bit.ly/DNSUKcourses.

2020 course dates:

Dynamic navigation for precise implant placement

1 May and 2 October

Venue: The White Bridge Dental

Practice, Kidlington, Oxford

Fees: $£ 395$ (Early bird discount $£ 350$ )

Booking: call 07341817116 or email amitkmohindra@gmail.com.

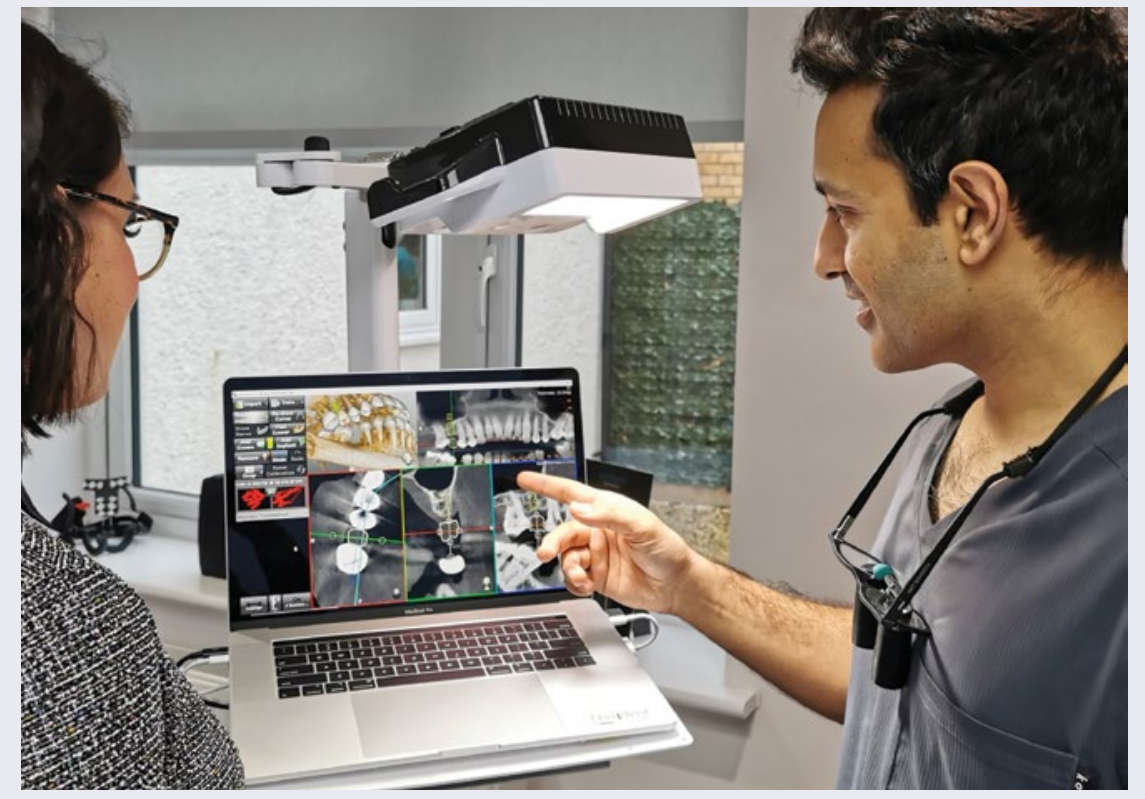

\section{Water way to floss}

Waterpik has developed convenient cordless water flossers as well as countertop models and Complete Care units supplied with specially designed tips to ensure there is a Waterpik Water Flosser for all patient needs.

There is also the innovative Waterpik Whitening Water Flosser for superior stain removal and now the world's first flossing toothbrush, the Waterpik Sonic-Fusion clinically proven to be up to two times as

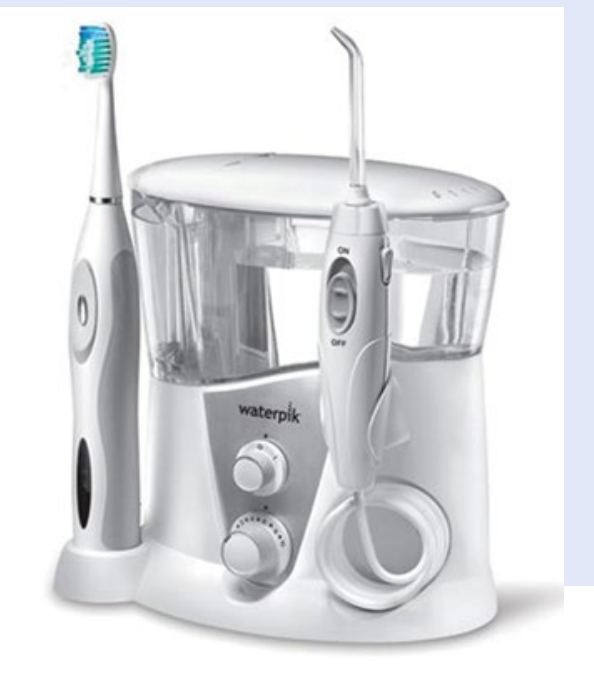

effective as standard brushing and flossing for removing plaque and improving gingival health.

All backed by over 60 clinical studies, discover the Waterpik oral health product range now.

For more information on Waterpik products visit waterpik.co.uk. Waterpik products are available from Amazon, Asda, Costco UK, Boots and Superdrug online and in stores across the UK and Ireland. 